\title{
ISOLATION AND CHARACTERIZATION OF A PICHIA ANOMALA STRAIN: A PROMISING CANDIDATE FOR BIOETHANOL PRODUCTION
}

\author{
Nengguo Tao*, Yumei Gao, Yuejin Liu \\ College of Chemical Engineering, Xiangtan University, Xiangtan 411105, P.R. China
}

Submitted: June 24, 2010; Returned to authors for corrections: July 08, 2010; Approved: November 04, 2010.

\begin{abstract}
A yeast strain designated as Y-1 was isolated and characterized from wine yeast ("Jiuqu"). Based on the morphological and biochemical results, along with the rDNA internal transcribed spacer region (ITS), Y-1 was identified to be a Pichia anomala strain. Y-1 is an ethanol-tolerant strain, enduring ethanol concentrations of up to $14 \%$. Y-1 growth medium conditions were optimized, results showing good growth in medium with $\mathrm{pH}$ ranges from 3.5-6.5, temperature ranges from $25-30{ }^{\circ} \mathrm{C}$, and inoculums range of $8 \%-12$ $\%$, while optimum growth conditions were reached at a temperature of $30^{\circ} \mathrm{C}, \mathrm{pH} 5.0$, and inoculums of 10 $\%$. Furthermore, when the alkaline hydrolyzed Shatian pummelo peel solutions were inoculated with $10 \%$ Y-1 and fermented at $30{ }^{\circ} \mathrm{C}$ for $6 \mathrm{~d}, 4.7 \%$ pure ethanol $(\mathrm{w} / \mathrm{w})$ was produced, as evidenced by gas chromatography analysis. Our present study shows potential for the Y-1 strain to be a promising candidate for bioethanol production.
\end{abstract}

Key words: Bioethanol; gas chromatography analysis; Jiuqu; Pichia anomala

\section{INTRODUCTION}

With the challenges facing the world's energy security, growing attention has been devoted to the production of renewable and clean fuel alternatives to fossil fuels. One of the most prevalent renewable fuel sources is ethanol $(29,30)$. In many parts of the world, demand for ethanol as an alternative fuel source has steadily increased due to dwindling fossil fuel resources and increases in gasoline prices, as well as efforts in decreasing the overall amount of greenhouse gases emitted into the atmosphere $(11,32)$. Accordingly, ethanol fuel production from biomass at an industrial level shows great potential for satisfying future world energy demands (13).
The production of bioethanol is a biological process in which sugars such as glucose, fructose, and sucrose are converted into cellular energy by microbial fermentation and thereby produce ethanol and carbon dioxide as metabolic waste products. The microorganisms employed in the fermentation of sugars into ethanol are principally bacteria and yeasts (16). Yeasts have proven to be more robust than bacteria by being more tolerant to ethanol $(11,23)$. Yeast strains are highly desired with good enological properties, such as high fermentation activity, high yields of ethanol, tolerance to ethanol, high temperature, and growth at a high osmotic pressure $(2,7,26)$.

"Jiuqu," also called wine yeast or distiller's yeast, is produced with a technique that uses microbiological enzymes.

\footnotetext{
*Corresponding Author. Mailing address: College of Chemical Engineering, Xiangtan University, Xiangtan 411105, P.R. China.; Tel: 86- 731- 58292246 Fax: 86- 731-58293284.; E-mail: nengguotao@xtu.edu.cn
} 
This yeast has been selected by humans for more than 8000 years under conditions that favored the evolution towards several specialized features, such as fast growth in high-sugar fruit juices, high yield of and resistance to ethanol (14). The normally isolated strains from "Jiuqu" are yeasts, Rhizopus, and small quantities of Aspergillus(19). When compared to other industrial or laboratory strains, wine yeast strains usually exhibit a higher tolerance to ethanol and therefore produce high yields of ethanol. For this reason, there is a high demand for ethanol strains from "Jiuqu."

The main objective of this study was to isolate, identify and characterize a yeast strain from a local "Jiuqu." The effects of temperature, $\mathrm{pH}$ and inoculums of the isolated yeast strain on the culture process were also studied. In addition, ethanol production from citrus peel waste inoculated with the isolated yeast was observed.

\section{MATERIALS AND METHODS}

\section{Plant materials}

"Jiuqu" described herein was collected from the local winery. Fruits of Shatian pummelo (C. grandis Osbeck) were purchased from the supermarket of Xiangtan University, Xiangtan, China. Prior to hydrolysis, the peel of the Shatian pummelo fruit was subjected to a sterilization process in order to remove limonene, a monoterpene that inhibits yeast and other microorganism (30). After sterilization peels were dried at $40{ }^{\circ} \mathrm{C}$ and ground into powder for further use.

\section{Yeast isolation}

One gram of "Jiuqu" was added into $100 \mathrm{ml}$ of sterilized physiological saline. The suspension was serially diluted with sterilized distilled water. A $0.1 \mathrm{ml}$ aliquot of the diluted suspension was spread on the YPD medium containing $1 \%$ yeast extract, $2 \%$ peptone, $2 \%$ dextrose and $2 \%$ agar. The plates were incubated at $28{ }^{\circ} \mathrm{C}$ for $2 \sim 3 \mathrm{~d}$. The predominant representative colonies were selected based on colony morphology differences under a microscope. Selected colonies were sub-cultured on new plates and purified by repeated streaking. The isolated colonies were maintained on YPD agar slants at $4{ }^{\circ} \mathrm{C}$ for further identification.

\section{Phenotypic identification of the isolated yeast}

The purified yeast colonies were subjected to standard tests and classification schemes as described by Kreger-van Rij (1984) (17).

\section{Molecular characterization}

The molecular method for yeast identification was based on the amplification and sequence analysis of the ribosomal DNA internal transcribed spacer region (ITS) (5). The primers used to amplify the rDNA internal transcribed spacer region were ITS1 (5'-CGG GATCCGTAGGTGAACCTGCGG-3') and ITS4 (5'-CGGGATCCTCCGCTTATTGAT ATGC-3'). The amplification reaction was done in $20 \mu$ (final volume) containing 20 pmol of each primer, $300 \mathrm{ng}$ of genomic DNA template, $0.2 \mathrm{mM} \mathrm{dNTP}, 1.5 \mathrm{mM} \mathrm{MgCl}_{2}$ and $1 \mathrm{U}$ Taq polymerase. The reactions were run for 40 cycles with denaturation at $94{ }^{\circ} \mathrm{C}$ for $1 \mathrm{~min}$, annealing at $55{ }^{\circ} \mathrm{C}$ for $1 \mathrm{~min}$, and extension at $72{ }^{\circ} \mathrm{C}$ for $2 \mathrm{~min}$. The PCR products were cloned into the pMD18-T vector and sequenced. Sequences of the PCR product were compared with the ITS region deposited in the GenBank (http://www.ncbi.nlm.nih.gov) and the percentage of similarity among the fragments was calculated using the BLAST program (http://www.ncbi.nlm.nih.gov/ $\underline{\text { BLAST/). }}$

\section{Ethanol tolerance}

The yeast isolates were inoculated in $10 \mathrm{ml}$ of liquid YPD (10 g/l yeast extract, $10 \mathrm{~g} / \mathrm{l}$ peptone, $20 \mathrm{~g} / \mathrm{l}$ glucose) supplemented with 80,100,120,140 and $160 \mathrm{ml} / \mathrm{l}$ ethanol and incubated at $28{ }^{\circ} \mathrm{C}$ for one week. The increase in cell number was determined by the gas amount collected in the Durham's tubes. 


\section{Determination of growth parameters of the isolated yeast}

Temperature: Overnight cultures of the yeast strain were centrifuged at $5000 \mathrm{rpm}$ for $10 \mathrm{~min}$ and cells were washed twice with sterilized normal saline. Then, cells were suspended in the same solution to give a concentration of about $10^{7}$ $\mathrm{cfu} / \mathrm{ml}$. An aliquot of $10 \mu \mathrm{l}$ suspension was inoculated into the YPD liquid medium and incubated at $25^{\circ} \mathrm{C}, 30{ }^{\circ} \mathrm{C}, 35^{\circ} \mathrm{C}, 40$ ${ }^{\circ} \mathrm{C}, 45^{\circ} \mathrm{C}$ for $72 \mathrm{~h}$. The increase in cell number was determined by measuring the optical density (OD) of cultures at $600 \mathrm{~nm}$.

pH: Activated yeast was inoculated into YPD liquid medium with varying $\mathrm{pHs}$. The $\mathrm{pH}$ of the broth was adjusted to 3.0, 3.5, 4.0, 4.5, 5.0, 5.5, 6.0, 6.5, 7.0 and 7.5 by sodium hydroxide or sulfuric acid. All pH measurements were done on an Orion $710 \mathrm{~A} \mathrm{pH}$ meter equipped with a glass electrode calibrated for $\mathrm{H}^{+}$ion concentration. After growth at $30{ }^{\circ} \mathrm{C}$ for $24 \mathrm{~h}$, the OD value of each broth was determined at $600 \mathrm{~nm}$ by a spectrophotometer.

Inoculum: Overnight cultures of the yeast strain were centrifuged at $5000 \mathrm{rpm}$ for $10 \mathrm{~min}$ and cells were washed twice with sterilized physiological saline $(\mathrm{NaCl} 8.5 \mathrm{~g} / \mathrm{l})$. Then, cells were suspended in the same solution to give a concentration of $0.01 \mathrm{~g} / \mathrm{ml}$, and a specified volume of the strain suspension was added into the YPD liquid medium to reach 6 $\%, 8 \%, 10 \%, 12 \%, 14 \%$ inoculation quantity. After growth at $30{ }^{\circ} \mathrm{C}$ for $24 \mathrm{~h}$, the $\mathrm{OD}$ value of each broth was determined at $600 \mathrm{~nm}$ by a spectrophotometer.

The orthogonal experiment: Based on the single factor experiments, a $\mathrm{L}_{9}\left(3^{3}\right)$ orthogonal experimental design was used to investigate the effect of A (temperature: $25{ }^{\circ} \mathrm{C}, 30{ }^{\circ} \mathrm{C}, 55$ ${ }^{\circ} \mathrm{C}$ ), B (pH: 4.0, 4.5, 5.0) and $\mathrm{C}$ (inoculum: $8 \%, 10 \%, 12 \%$ ) on the culture process.

\section{Fermentation condition and analytical techniques}

Ten grams of dry peel powder of Shatian pummelo was suspended in $150 \mathrm{ml}$ of $10 \% \mathrm{NaOH}$. After soaking in $10 \%$ $\mathrm{NaOH}$ for $20 \mathrm{~min}$, a proper amount of $6 \mathrm{M} \mathrm{H}_{2} \mathrm{SO}_{4}$ solution was added to adjust the $\mathrm{pH}$ to 5.0. Then the solution was filtered through a piece of gauze and $150 \mathrm{ml}$ filtrate was obtained. The sterilized solution was inoculated with $10 \%$ Y-1. After fermenting at $30{ }^{\circ} \mathrm{C}$ for $6 \mathrm{~d}$, enough $\mathrm{CaO}$ was added to the fermentation broth to remove the water. The resulting solutions were subjected to distillation and were analyzed by a Capillary Gas Chromatogram. The column was FFAP $(0.32 \mathrm{~mm} \times 30 \mathrm{~m}$, $0.25 \mu \mathrm{m})$. The column temperature was increased from $50{ }^{\circ} \mathrm{C}$ to $120^{\circ} \mathrm{C}$, and the rate was $10{ }^{\circ} \mathrm{C} / \mathrm{min}$. The FID temperature was set at $240{ }^{\circ} \mathrm{C}$, and the carrier gas was nitrogen whose flow rate was $5 \mathrm{ml} / \mathrm{min}$. The internal standard was n-butanol.

\section{RESULTS}

\section{Isolation and identification of the isolated yeast}

A yeast strain, designated as Y-1, was successfully isolated from the local "Jiuqu." The colony morphology of this strain was ivory-white in color, smooth with a finely serrate margin (Figure 1). It could form one ascospore (Figure 2), and no pseudo-hypha was observed during cultivation. In the fermentation sugar source test, it was capable of utilizing almost all the test sugars (glucose, maltose, sucrose, galactose and raffinose) except lactose (Table 1). In the assimilation carbon source test, it could make use of the entire tested carbon source except methanol (Table 1). Y-1 could assimilate both ammonium sulfate and potassium nitrate. In addition, Y-1 could grow well on the substrate without vitamins and with high osmotic pressure. It also had the potential ability to produce a compound similar to starch. According to these morphological properties, Y-1 was preliminary identified to be a Pichia anomala (=Hansenula anomala) strain $(5,17)$.

To confirm the taxonomic identity of $\mathrm{Y}-1$, the $18 \mathrm{~s}$ rDNA ITS region was cloned and sequenced. After PCR amplification using the ITS1 and ITS4 primer combinations, a fragment about 600 bp in size was obtained (Figure 3). Sequencing results revealed that it was $617 \mathrm{bp}$ in length (Figure 4). BLAST results showed that it shared complete identity with the corresponding sequences of Pichia anomala (EU343844, 
AB469881, AB467307, and EU380207) deposited in

GenBank. Based on these results, Y-1 was identified to be a Pichia anomala strain.

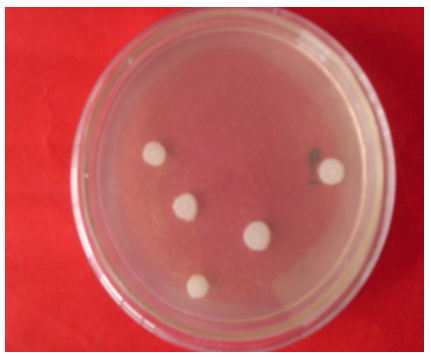

A. The face of medium

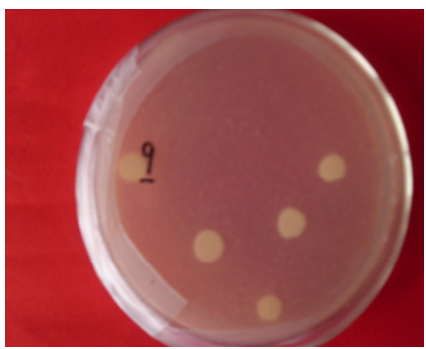

B. The inverse of medium
Figure 1. The pictures of purified yeast strains in the medium

Figure 2. The ascospore morphological characters of Y-1

Table 1. Biochemical characteristics of Y-1

\begin{tabular}{lc}
\hline \multicolumn{1}{c}{ Characteristic } & results \\
\hline Sugar fermentation & + \\
1.Glucose & + \\
2.Maltose & + \\
3.Sucrose & - \\
4.Lactose & + \\
5.Galactose & + \\
6.Raffinose & \\
Carbon sources assimilation & + \\
7.Lactose & + \\
8.Xylose & + \\
9.Arabinose & + \\
10.Citric Acid & + \\
11.Amidulin & - \\
12.Methanol & + \\
13.Glycerin & + \\
Assimilative capacity of ammonium sulfate & + \\
Assimilative capacity of potassium nitrate & + \\
The growth on the substrate without vitamin & $\mathrm{v}$ \\
Producing similar starch compound & + \\
The growth on the substrate with high osmotic pressure & + \\
\hline Note "+" mean positive; "“" negative, "v" mean variable. & \\
&
\end{tabular}

\section{2}

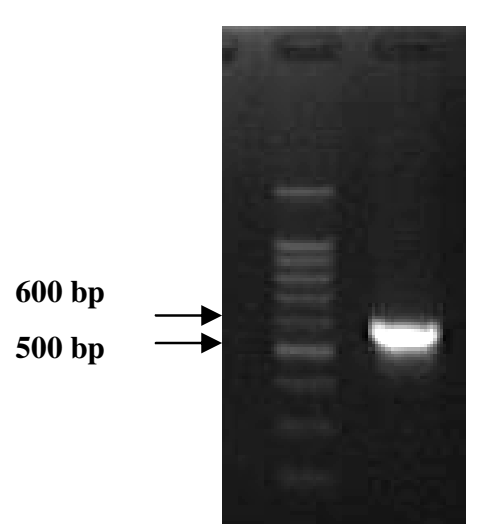

Figure 3. PCR product of the ITS region of Y-1. Lane 1: 100 bp DNA ladder, lane 2: the PCR product.

TCCGTAGGTGALCTGCGGAGGATCATTATAGTATTCTATTGCCAGCGCTTAATTGCGGGCGATAнACCTTACACAC ITS1

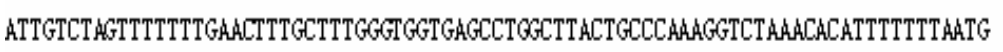

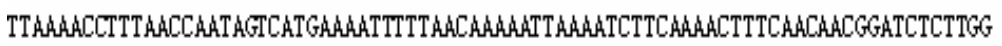

TTCTCGCAACGATGAHGAHOCLAGCGAAATOCGATACGTATTGTGATTGCAGATTTTCGTGAATCATCGAATCTTTGA

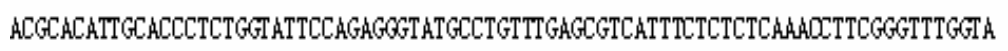

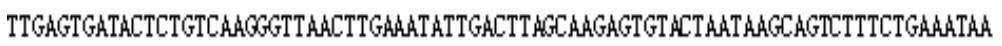

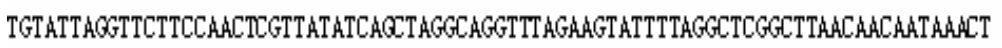

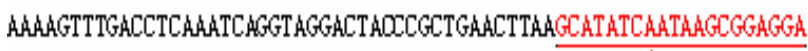

ITS4

Figure 4. Sequencing results of the ITS region of Y-1. Primer sequences were underlined

\section{Ethanol tolerance}

Table 2 shows the effect of ethanol on the growth rate of Y-1. As revealed by Table 2, Y-1 could grow well in the presence of $8 \%$ and $10 \%$ ethanol. The growth of Y-1 was remarkably inhibited with the increase of exogenously added ethanol. Only 3/4 gas of the Durham's tube was obtained in the presence of $12 \%$ ethanol, and even half the amount of gas was present in the tube in the presence of $14 \%$ ethanol. The growth of Y-1 was severely inhibited in the presence of $16 \%$ and 18 $\%$ ethanol, since no gas was released. Consequently, it could be inferred that Y-1 was able to endure $14 \%$ ethanol. 
Table 2. Ethanol endurance of $\mathrm{Y}-1$

\begin{tabular}{ccccccc}
\hline & \multicolumn{7}{c}{ Ethanol Degree (v/v) } \\
\cline { 2 - 7 } & $8 \%$ & $10 \%$ & $12 \%$ & $14 \%$ & $16 \%$ & $18 \%$ \\
\hline $\mathrm{Y}-1$ & ++++ & ++++ & +++ & ++ & - & - \\
\hline
\end{tabular}

++++: the Durham's fermentation tube was full of gas; +++: the Durham's fermentation tube was filled with 3/4 gas; ++: the Durham's fermentation tube was filled with $1 / 2$ gas; -: no gas was observed

\section{Optimization of culture conditions}

Temperature: As revealed by Figure 5A, the OD value increased as temperatures increased from $25^{\circ} \mathrm{C}$ to $30^{\circ} \mathrm{C}$, and then declined when the temperatures were above $30{ }^{\circ} \mathrm{C}$. A sharp decrease of OD values was detected when the temperature increased from $35^{\circ} \mathrm{C}$ to $45^{\circ} \mathrm{C}$. The $\mathrm{OD}$ value almost reached zero at $40^{\circ} \mathrm{C}$ and $45^{\circ} \mathrm{C}$, suggesting that $40{ }^{\circ} \mathrm{C}$ might be a lethal temperature for Y-1.

pH: The effects of $\mathrm{pH}$ on the yeast cell growth are given in Figure 5B. The OD value increased by a fraction when the $\mathrm{pH}$ ranged from 3.0 to 4.5 , while 4.5 was obviously the optimal $\mathrm{pH}$ for $\mathrm{Y}-1$. The medium $\mathrm{pH}$ fluctuation between 5.0 and 6.0 did not significantly affect the growth rate of $\mathrm{Y}-1$. When the $\mathrm{pH}$ ranged from 6.5 to 7.5 , it underwent a remarkable decrease in OD, reducing from 0.997 to 0.415 .

Inoculum: The effect of inoculum on the fermentation process was shown in Figure 5C. The biomass increased steadily when the inoculums varied from $6 \%$ to $10 \%$. There was a moderate decrease when the inoculums varied from $10 \%$ to $12 \%$. In contrast, a notable decease was observed between inoculums of $12 \%$ and $14 \%$.

Orthogonal experiment: The optimal conditions for the culture process were obtained by using orthogonal design $\mathrm{L}_{9}$ $\left(3^{3}\right)$ based on single factor experiments. Table 3 showed factors at different levels in nine experiments conducted and the statistical analysis. Results showed that the order of the effect of factors affecting the fermentation process was found to be: $\mathrm{B}>\mathrm{A}>\mathrm{C}$. The optimum culture conditions obtained from the statistical analysis were $\mathrm{A}_{2} \mathrm{~B}_{3} \mathrm{C}_{2}$. The optimal culture conditions for $\mathrm{Y}-1$ were suggested to be at a temperature of 30 ${ }^{\circ} \mathrm{C}, \mathrm{pH} 5.0$ and inoculums of $10 \%$. These conditions were later tested to ascertain the reliability of these results. As a result, the OD value in the experimental result was 2.56 , higher than results in the orthogonal experiment. Therefore, the hypothesis of the orthogonal experiment was valid.
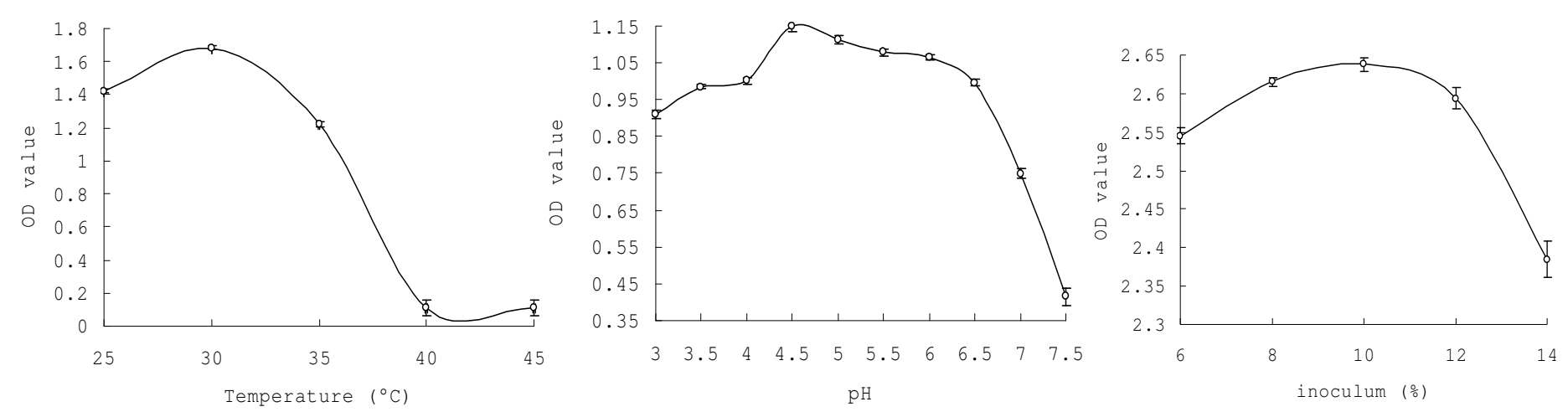

Figure 5. Influences of temperature (A), $\mathrm{pH}(\mathrm{B})$, inoculum(C) on the growth of Y-1 
Table 3. The experimental designs and the orthogonal test results

\begin{tabular}{ccccc}
\hline Run & A & B & C & OD value \\
\hline 1 & 1 & 1 & 1 & 2.184 \\
2 & 1 & 2 & 2 & 2.347 \\
3 & 1 & 3 & 3 & 2.411 \\
4 & 2 & 2 & 3 & 2.393 \\
5 & 2 & 3 & 1 & 2.346 \\
6 & 2 & 1 & 2 & 2.341 \\
7 & 3 & 3 & 2 & 2.396 \\
8 & 3 & 1 & 3 & 2.094 \\
9 & 3 & 2 & 1 & 2.174 \\
\hline $\mathrm{K}_{1}$ & 6.942 & 6.619 & 6.704 & \\
$\mathrm{~K}_{2}$ & 7.080 & 6.914 & 7.084 & \\
$\mathrm{~K}_{3}$ & 6.664 & 7.153 & 6.898 & \\
$\mathrm{k}_{1}$ & 2.314 & 2.206 & 2.235 & \\
$\mathrm{k}_{2}$ & 2.360 & 2.305 & 2.361 & \\
$\mathrm{k}_{3}$ & 2.221 & 2.384 & 2.299 & \\
$\mathrm{R}$ & 0.139 & 0.178 & 0.126 & \\
\hline
\end{tabular}

\section{The yield of ethanol from alkaline hydrolyzed citrus peel}

When the fermentation broth was distilled, about $6 \mathrm{ml}$ of ethanol solution was obtained. It was then analyzed by Gas chromatography. As revealed by Figure 6A and 6B, only one peak of the collected sample was observed, which was consistent with the typical peak of the ethanol standard. The yield of ethanol was calculated to be $46.9 \pm 1.25 \mathrm{~g} / \mathrm{l}$.
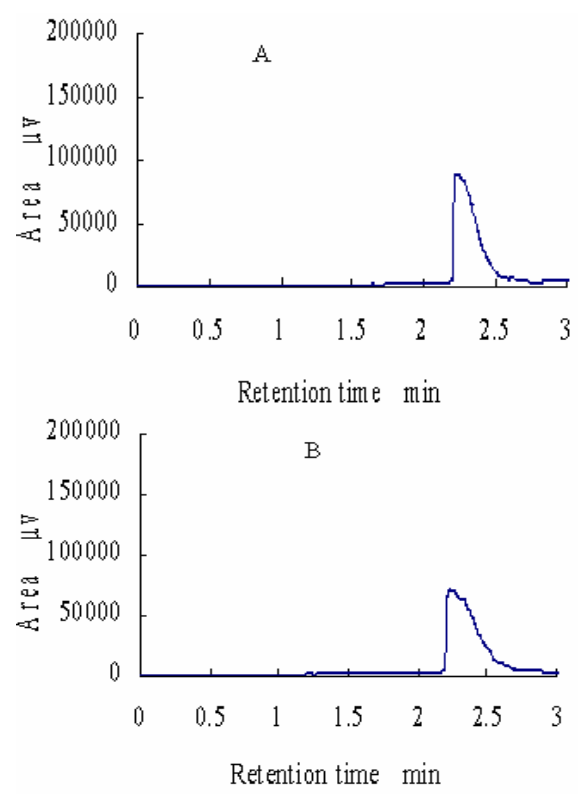

Figure 6. GC analysis of the ethanol (A: samples; B: the ethanol standard)

\section{DISCUSSION}

It is commonly believed that in a natural or spontaneous fermentation non-Saccharomyces yeasts such as Candida, Debaryomyces, Hanseniaspora, Hansenula, Kloeckera, Metschnikowia, Pichia, Schizosaccharomyces, Torulaspora, Zygosaccharomyces and many others grow and participate in early stages of fermentation (15). As the fermentation proceeds, the ethanol concentration increases. This (high ethanol) limits the growth and activity of the native nonSaccharomyces yeasts thus creating a condition favorable to the growth and domination of native Saccharomyces yeast, which then conduct the fermentation $(12,19)$. Therefore, bioethanol is dominantly produced by different Saccharomyces cerevisiae strains $(10,11,21,22)$. However, recent researches, as well as our present study, indicate that in many cases nonSaccharomyces strains also showed potential for ethanol production. A previous study revealed that ethanol yields produced by Kluyveromyces marxianus from hydrolyzed Valencia orange peel waste could be $37.1 \mathrm{~g} / \mathrm{l}$, close to that of $40.9 \mathrm{~g} / 1$ by Saccharomyces cerevisiae (30). The ethanol produced by Kluyveromyces marxianus in shaking flask cultivation in sugar cane juice media at $37{ }^{\circ} \mathrm{C}$ reached $8.7 \%$ 
(w/v), productivity $1.45 \mathrm{~g} / \mathrm{l} / \mathrm{h}$ and yield $77.5 \%$ of theoretical yield (20). Tomás-Pejó et al (28) reported that the ethanol concentration from wheat straw by the thermotolerant yeast Kluyveromyces marxianus could be 36.2 g/l. In our present study, the final ethanol yield from hydrolyzed Shatian pummelo peel waste was measured to be $46.9 \mathrm{~g} / \mathrm{l}$, which was near the theoretical value (33).

Ethanol endurance is an important property concerning fermentation efficiency. Ethanol is a well known toxic metabolite for yeast cells. Ethanol stress inhibits the amino acid transport system and glucose transport, and can lead to the loss of cell viability and the inhibition of cell growth $(1,18,25)$. The rates of ethanol production are reduced with the accumulation of ethanol in the culture broth, especially when high concentrations of sugar substrates are used (24). Therefore, industrial yeast with high ethanol tolerance is highly desired for the improvement of ethanol concentration. It was generally accepted that $S$. cerevisiae was the most ethanoltolerant species (9), with an average ethanol endurance of $12 \%$ (v/v), which varies depending on the strain (27). However, our present data supports that non-S. cerevisiae yeasts may also be ethanol-tolerant, given that Y-1 was able to endure $14 \%$ of ethanol.

In the conversion process of sugars to ethanol, growth of microorganisms was highly linked with the stress or environmental factors in the culture medium, which thereby affected the fermentation efficiency (3). These factors included temperature, osmotic stress, anaerobic conditions, heavy metals, growth regulators, ultraviolet radiation, metabolic repressors, $\mathrm{pH}$ and so on $(4,6,8,11,28,31)$. Consequently, a sound understanding of these factors is essential to achieve a successful fermentation and an increased ethanol yield. Our present study demonstrated that the optimum culture condition for $\mathrm{Y}-1$ was a temperature of $30{ }^{\circ} \mathrm{C}, \mathrm{pH} 5.0$, and inoculums of $10 \%$, which was similar to those of some $S$. cerevisiae strains in bioethanol production, suggesting that $\mathrm{Y}-1$ could also be widely used in the ethanol industry.
In conclusion, we have successfully isolated a Pichia anomala strain from Jiuqu, which demonstrated tolerance to high ethanol concentrations and showed potential as an ideal strain for bioethanol production.

\section{ACKNOWLEDGEMENTS}

This work was supported by National Natural Science Foundation of China (No. 30901010), Hunan Provincial Natural Science Foundation of China (No.08JJ6020), Scientific Research Fund of Hunan Provincial Education Department (No.08C891) and International Foundation for Science (No.F/4589-1). Thanks should also be expended to Dr. Jiang Zhang, Department of Biochemistry and Molecular Biology, Mississippi State University, USA, for his critical reviewing of this manuscript.

\section{REFERENCE}

1. Alexandre, H.; Charpentier C. (1998). Biochemical aspects of stuck and sluggish fermentation in grape must. J. Ind. Microbiol. Biot., 20: 20-27.

2. Altíntas, M.; Ülgen, K.Ö.; Kırdar, B. ; Önsan, Z.I. ; Oliver, S.G. (2002). Improvement of ethanol production from starch by recombinant yeast through manipulation of environmental factors. Enzyme Microb. Tech., 31: 640-647.

3. Banat, I.; Nigam, P.; Singh D.; Marchant, R.; McHale, A.P. (1998). Review: ethanol production at elevated temperatures and alcohol concentrations: Part I - Yeasts in general. World J. Microb. Biot., 14: 809-812.

4. Bandaru V.V.R.; Somalanka S.R.; Menduc D.R.; Madicherlab, N.R.; Chityala, A. (2006). Optimization of fermentation conditions for the production of ethanol from sago starch by co-immobilized amyloglucosidase and cells of Zymomonas mobilis using response surface methodology. Enzyme Microb. Tech., 38: 209 -214.

5. Caggia C.; Restuccia C.; Pulvirenti A.; Giudici, P. (2001). Identification of Pichia anomala isolated from yoghurt by RFLP of the ITS region. Int. J. Food Microbiol., 71: 71-73.

6. Cakar Z.; Seker U.; Tamerler C.; Sonderegger, M.; Sauer, U. (2005). Evolutionary engineering of multiple-stress resistant Saccharomyces cerevisiae. FEMS Yeast Res., 5: 569-578.

7. Chen, G.; Yao, S.J.; Guan, Y.X. (2006). Influence of osmoregulators on osmotolerant yeast Candida krusei for the production of glycerol. 
Chinese J. Chem. Eng., 14: 371-376.

8. Chen, K.; Chen, Z. (2004). Heat shock proteins of thermophilic and thermotolerant fungi from Taiwan. Bot. Bull. Acad. Sinica, 45: 247-56.

9. Cocolin, L.; Bisson, L.F.; Mills, D.A. (2000). Direct profiling of the yeast dynamics in wine fermentations. FEMS Microbiol. Lett., 189: 8187.

10. Dawson, L.; Boopathy, R. (2007). Use of post-harvest sugarcane residue for ethanol production. Bioresource Technol., 98: 1695-1699.

11. Edgardo, A.; Parra, C.; Manuel, R.; Juanita, F.; Baeza, J. (2008). Selection of thermotolerant yeast strains Saccharomyces cerevisiae for bioethanol production. Enzyme Microb. Tech., 43: 120-123.

12. Esteve-Zarzoso B.; Manzanares, P.; Ramón, D.; Querol, A. (1998). The role of non-Saccharomyces yeasts in industrial winemaking. Int. Microbiol., 1: 143-148.

13. Farrell, A.E.; Plevin, R.J.; Turner, B.T.; Jones, A.D.; O'Hare, M.; Kammen, D.M. (2006). Ethanol can contribute to energy and environmental goals. Science, 311: 506- 508.

14. Hauser, N.C.; Fellenberg K.; Gil, R.; Bastuck, S.; Hoheisel, J.D.; PérezOrtín, J.E. (2001). Whole genome analysis of a wine yeast strain. Comp. Funct. Genom., 2: 69-79.

15. Jolly, N.P.; Augustyn, O.P.H.; Pretorius, I.S. (2003). The effect of nonSaccharomyces yeasts on fermentation and wine quality. S. Afr. J. Enol. Vitic., 24: 55-62.

16. Klinke, H.; Thomsen, A.; Ahring, B. (2004). Inhibition of ethanolproducing yeast and bacteria by degradation products produced during pre-treatment of biomass. Appl. Microbiol. Biot., 66:10-26.

17. Kreger-van, Rij. (1984). The yeast: a taxonomic study. Third revised and enlarged edition. The Netherlands: Elsevier Science Publishers BV.

18. Lei, J.J.; Zhao, X.Q.; Ge, X.M.; Bai, F.W. (2007). Ethanol tolerance and the variation of plasma membrane composition of yeast floc populations with different size distribution. J. Biotechnol., 131: 270-275.

19. Li, J.R.; Cai, A.Q. (2007). Isolation and identification of main microorganisms in traditional distiller's yeast. Liquor-Making Sci. Tech., 5: 111-115 (In Chinese with English abstract).

20. Limtong, S.; Sringiew, C.; Yongmanitchai, W. (2007). Production of fuel ethanol at high temperature from sugarcane juice by a newly isolated Kluyveromy cesmarxianus. Bioresource Technol., 98: 3367-3374.

21. Mishima, D.; Kuniki, M.; Sei, K.; Soda, S.; Ike, M.; Fujita, M. (2008). Ethanol production from candidate energy crops: water hyacinth (Eichhornia crassipes) and water lettuce (Pistia stratiotes L.). Bioresource Technol., 99: 2495-2500.
22. Olofsson, K.; Rudolf, A.; Liden, G. (2008). Designing simultaneous saccharification and fermentation for improved xylose conversion by a recombinant strain of Saccharomyces cerevisiae. J. Biotechnol., 134: $112-120$.

23. Olsson, L.; Hahn-Hagerdal, H. (1996). Fermentation of lignocellulosic hydrolysates for ethanol production. Enzyme Microb. Tech., 18: 312-331.

24. Piper, P.W. (1995). The heat shock and ethanol stress responses of yeast exhibit extensive similarity and functional overlap. FEMS Microbiol. Lett., 134: 121-127.

25. Sanches, P.M.; Laluce, C. (1998). Ethanol tolerance of thermotolerant yeasts cultivated on mixtures of sucrose and ethanol. J. Ferment. Bioeng., 85: 388- 397.

26. Szczodrak, J.; Targonsky, Z. (1988). Selection of thermotolerant yeast strains for simultaneous saccharification and fermentation of cellulose. Biotechnol. Bioeng., 31: 300-303.

27. Tofalo, R.; Chaves-Lopez, C.; Fabio, F.D.; Schirone, M.; Felis, G.E.; Torriani, S.; Paparella, A.; Suzzi, G. (2009). Molecular identification and osmotolerant profile of wine yeasts that ferment a high sugar grape must. Int. J. Food Microbiol., 130: 179-187.

28. Tomás-Pejó, E.; Oliva, J.M.; Gonzalez, A.; Ballesteros, I.; Ballesteros, M. (2009). Bioethanol production from wheat straw by the thermotolerant yeast Kluyveromyces marxianus CECT 10875 in a simultaneous saccharification and fermentation fed-batch process. Fuel, 88: 2142-2147.

29. Walter, B. (2006). Batch ethanol fermentation: the correlation between the fermentation efficiency and the biomass initial concentration depends on what is considered as produced ethanol. Braz. J. Microbiol., 37: 8789.

30. Wilkins, M.R.; Suryawati, L.; Chrz, D. (2007). Ethanol production by Saccharomyces cerevisiae and Kluyveromyces marxianus in the presence of orange peel oil. World J. Microb. Biot., 23: 1161-1168.

31. Xu, Q.Q.; Lu, L.X.; Chen, S.Y.; Zheng, J., Zheng, G.L.; Li, Y.Q. (2009). Isolation of Cordyceps ophioglossoides L2 from fruit body and optimization of fermentation conditions for its mycelial growth. Chinese J. Chem. Eng., 17: 278-285.

32. Yu, Z.S.; Zhang, H.Y. (2004). Ethanol fermentation of acid-hydrolyzed cellulosic pryolysate with Saccharomyces cerevisia. Bioresource Technol., 93: 199-204.

33. Zhou, W.Y.; Widmer, W.; Grohmann, K. (2007). Economic analysis of ethanol production from citrus peel waste. Proc. Fla. State. Hort. Soc., 120: $310-315$

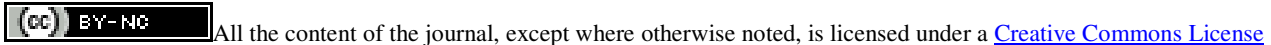

